ADVERSE DRUG REACTION

\title{
Retinal vein thrombosis associated with a herbal phytoestrogen preparation in a susceptible patient
}

\section{J L Cheong, R Bucknall}

Postgrad Med J 2005;81:266-267. doi: 10.1136/pgmj.2004.026369

A 55 year old woman, known to have systemic lupus erythematosus and protein $\mathrm{S}$ deficiency, presented with sudden onset of visual loss in the left eye. Three days previously, she took a herbal phytoestrogen preparation for relief of her menopausal symptoms. Ophthalmological assessment showed a left inferior hemiretinal vein thrombosis. The temporal relation between the onset of visual symptoms and ingestion of this herbal preparation suggested that in this patient with a prior non-manifest prothrombotic tendency, there may be an association between the development of retinal vein thrombosis and herbal phytoestrogen use.

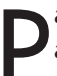
atients with prothrombotic tendencies should be warned against using herbal phytoestrogen preparations. Oestrogen supplements are known to cause deep vein thrombosis, pulmonary embolism, and retinal vein thrombosis. We report a case of hemiretinal vein thrombosis precipitated by a herbal preparation in a susceptible patient.

\section{CASE REPORT}

A 55 year old woman, diagnosed with systemic lupus erythematosus and protein S deficiency, presented to the eye casualty department with sudden loss of vision in her left eye. Three days previously, she had taken a herbal preparation for relief of her menopausal symptoms.

She had a known $50 \%$ reduction in protein S activity and was taking regular prophylactic aspirin. She was negative for both anticardiolipin antibodies and lupus anticoagulant. She had not previously suffered from thrombosis.

On examination, she was normotensive with a blood pressure of 140/70. The visual acuity in her left eye was 6/36. Her right eye was normal. She had no afferent pupillary defect. Anterior segments and intraocular pressures were normal. Fundal examination showed a left inferior hemiretinal vein thrombosis (fig 1), which was subsequently confirmed on fluorescein angiography (fig 2).

Investigations showed normal haematological parameters, biochemistry including glucose, lipid, and homocysteine values, clotting, plasma viscosity, and inflammatory markers. Electrocardiogram, echocardiogram, and carotid Doppler were normal.

She stopped taking the herbal preparation and was treated conservatively with good visual recovery within three months. She was advised to take clopidogrel in addition to aspirin and has not had any further thrombotic episodes.

\section{DISCUSSION}

Aetiological factors for the development of retinal vein thromboses include hypertension, raised intraocular pressure, and prothrombotic tendencies such as the antiphospholipid syndrome although most cases are idiopathic. This patient suffered a retinal vein thrombosis, which can have long term sequelae including the development of proliferative retinopathy and neovascular glaucoma. To date, there have been no reports implicating a herbal preparation as a possible aetiological factor in the development of retinal vein thrombosis.

This herbal preparation contains several ingredients (black cohosh $250 \mathrm{mg}$, dong quai $100 \mathrm{mg}$, red clover $250 \mathrm{mg}$, and wild Mexican yam $276 \mathrm{mg}$; composition per tablet) with phytoestrogenic properties. Phytoestrogens are natural plant oestrogens with similar effect to human oestrogen but lower in concentration and potency.

Phytoestrogens are believed to act like selective oestrogen receptor modulators. Selective oestrogen receptor modulators such as raloxifene increase the risk of venous thromboembolism by a factor of $1.5-3,{ }^{1}$ and, like other oestrogenic compounds, phytoestrogens might carry the same risk.

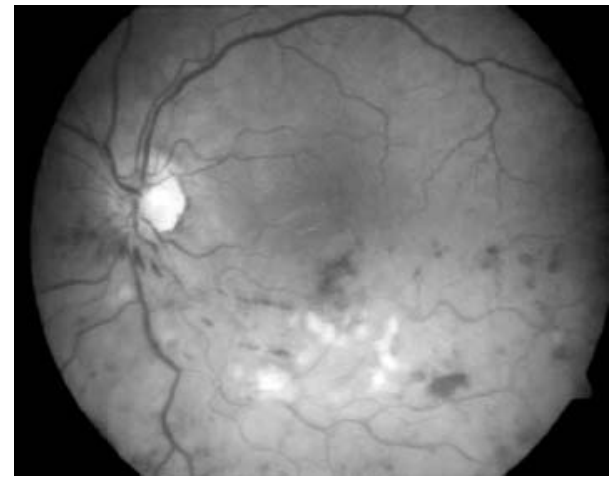

Figure 1 Fundal photograph showing a left hemiretinal vein thrombosis.

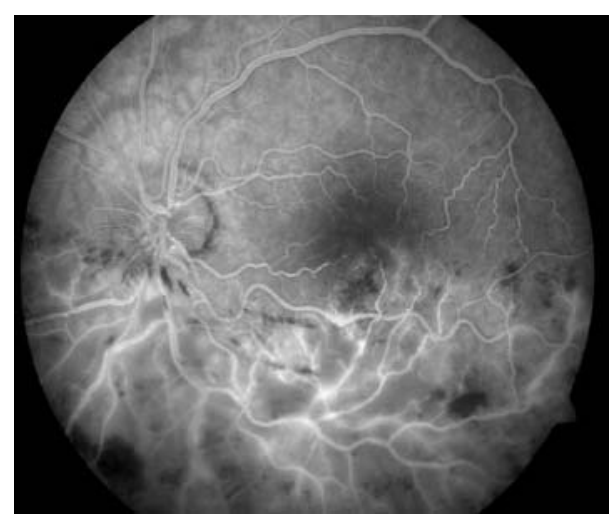

Figure 2 Fluorescein angiogram of left fundus. 


\section{Summary points}

- Oestrogen based herbal preparations are being used increasingly.

- Patients with prothrombotic tendencies need to be informed fully about hormone replacement therapy as well as oestrogen based preparations.

- Manufacturers of herbal preparations are not required to report adverse events to health authorities.

- The duty therefore lies with the healthcare professional.

Systemic lupus erythematosus, in the absence of anticardiolipin antibodies and lupus anticoagulant, is not associated with a prothrombotic tendency. There are, however, reports showing the presence of antibodies directed against protein $S$ in systemic lupus erythematosus, thereby reducing the activity of protein $S .^{2}$

Protein $\mathrm{S}$ is a vitamin $\mathrm{K}$ dependent, anticoagulant plasma protein $^{3}$ that increases the anticoagulant activity of protein C. ${ }^{4}$ Protein S deficiency is associated with an increased risk of venous thrombosis. ${ }^{5}$

Short term use of oestrogens can precipitate retinal vein thrombosis within a week of administration ${ }^{6}$ in patients without any prothrombotic tendencies. There is also evidence to suggest that low dose oral contraceptives can precipitate thrombosis. ${ }^{7}$

Although retinal vein thrombosis in this patient may have occurred spontaneously, the temporal relation and the oestrogenic content of this herbal preparation led us to believe that the latter has played a part in precipitating a thrombotic episode in this patient.

Herbal medicines are often self prescribed. The public and healthcare professionals may not be aware of potential adverse events, because manufacturers of herbal medicines are neither required to maintain records of adverse events nor to report them to health authorities. ${ }^{8}$
Herbal preparations are generally safe with high satisfaction rates among users. However, this case highlights the importance of fully informing patients with prothrombotic tendencies not only about the risks entailed with hormone replacement therapy but also with those associated with over the counter herbal phytoestrogen preparations. This report should encourage vigilance in other clinicians and increased reporting of these herbal remedy associated adverse events.

A CSM "yellow card" has been submitted for this adverse event.

\section{Authors' affiliations \\ J L Cheong, R Bucknall, Rheumatic Diseases Unit, Royal Liverpool University Hospital NHS Trust, Liverpool, UK}

Correspondence to: Dr J L Cheong, Rheumatic Diseases Unit, Link 7Z, Royal Liverpool University Hospital NHS Trust, Prescot Road, Liverpool L7 8XP, UK; jelai_cheong@hotmail.com

Submitted 1 July 2004

Accepted 7 August 2004

\section{REFERENCES}

1 Riggs BL. Selective estrogen-receptor modulators-mechanisms of action and application to clinical practice. N Engl J Med 2003;348:618-29.

2 Bertolaccini ML, Ralhan S, Gennari LC, et al. Antibodies directed to protein S in patients with systemic lupus erythematosus:prevalence and clinical significance. Thromb Haemost 2003:90:636-41.

3 Schwarz HP, Wencel-Drake JD, Griffin JH. Identification and quantification of protein S in human platelets. Blood 1985;66:1452-5.

4 High K. Antithrombin III, protein C, and protein S. Naturally occurring anticoagulant proteins. Arch Pathol Lab Med 1988;112:28-36.

5 Comp P, Esmon CT. Recurrent venous thromboembolism in patients with a partial deficiency of protein S. N Engl J Med 1984;311:1525-8.

6 Rousso DH, Karayannis V, Klearchou N, et al. Inferior temporal branch of the central retinal vein thrombosis associated with short-term estradiol valerate administration. Assisted Reproductive Technology/Andrology 1997;9:75-8.

7 Frohlich E. Vascular complications in women using the low steroid content combined oral contraceptive pills: case reports and review of the literature. Obstetr Gynecol Surv 1990;45:578-84.

8 Amato P. Review of alternative therapies for treatment of menopausal symptoms. Climacteric 2003;6:278. 
30 Inan MS, Rasoulpour RJ, Yin L, et al. The luminal short-chain fatty acid butyrate modulates NF-kappaB activity in a human colonic epithelial cell line. Gastroenterology 2000;118:724-34.

31 Luhrs H, Gerke T, Schauber J, et al. Cytokine-activated degradation of inhibitory $\kappa \mathrm{B}$ protein ais inhibited by the short-chain fatty acid butyrate. Int J Colorect Dis 2001;16:195-201.
32 Loncar MB, Al-azzeh ED, Sommer PS, et al. Tumour necrosis factor alpha and nuclear factor kappaB inhibit transcription of human TFF3 encoding a gastrointestinal healing peptide. Gut 2003;52:1297-303.

33 Loncar MB, Al-azzeh ED, Romanska H, et al. Transcriptional control of TFF3 (intestinal trefoil factor) via promoter binding sites for the nuclear factor kappaB and C/EBPbeta. Peptides 2004;25:849-54.

\section{CORRECTION}

doi: 10.1136/pmj.2004.026369corr l

An editorial error occurred in this paper by Drs J E Lai Cheong and R Bucknall (2005;81:266-7). The first author's name should have read J E Lai Cheong [not J L Cheong]. 